\title{
RESERVAS PARTICULARES DO PATRIMÔNIO NATURAL - O CASO DA RPPN ALTO DA BOA VISTA NO MUNICÍPIO DE DESCOBERTO/MG
}

\section{Thiago Corrêa Muniz ${ }^{1}$}

Resumo: O crescimento econômico baseado na exploração dos recursos da natureza, o crescimento urbano desordenado, a transformação de regiões de floresta em pastos e em campos agricultáveis, além de outros tipos de intervenção antrópica, tem trazido graves conseqüências como a degradação de vários biomas brasileiros, dentre eles a Mata Atlântica. Desta forma, torna-se necessária a busca de soluções para o enfrentamento da questão da dilapidação do patrimônio natural no Brasil. Uma das maneiras encontradas por alguns proprietários de terras ligados à causa da preservação ambiental, é a transformação de suas propriedades em Reservas Particulares do Patrimônio Natural. O presente artigo busca contribuir com o debate em torno da preservação dos remanescentes de Mata Atlântica abordando a criação das RPPNs no país e em particular a RPPN Alto da Boa Vista, no município de Descoberto, em Minas Gerais.

Palavras-chave: áreas de preservação; reservas particulares; legislação.

\section{INTRODUÇÃO}

\footnotetext{
${ }^{1}$ Licenciado em Geografia pela Universidade Federal de Juiz de Fora, professor do Centro Integrado SESI/SENAI Robson Braga de Andrade/ São João Nepomuceno, MG.
} 


\section{FÓRUM AMBIENTAL DA ALTA PAULISTA}

O presente artigo pretende contribuir, mesmo que de forma modesta, com o debate sobre a preservação dos remanescentes de Mata Atlântica. Em várias regiões de ocorrência desse bioma, um grupo seleto de pessoas está unido por um mesmo ideal, a preservação, e para isso transformaram as suas propriedades em Reservas Particulares do Patrimônio Natural (RPPN), que como veremos, são unidades de preservação reconhecidas pelo SNUC, o Sistema Nacional de Unidades de Conservação Brasileiro, instituído pela Lei Federal no 9.985 de 18 de Julho de 2000.

Neste artigo, apresentamos o trabalho desenvolvido em uma destas unidades de conservação, a RPPN Alto da Boa Vista, no município de Descoberto, Zona da Mata Mineira, que tem como proprietário o senhor Helvécio Rodrigues Pereira Filho. A partir do exemplo da reserva Alto da Boa Vista, espera-se mostrar a importância destas unidades de conservação na proteção do pouco que resta da diversidade biológica nesta região.

A história das Reservas Particulares do Patrimônio Natural (RPPN) no Brasil inicia-se em 23 de Janeiro de 1934 com a instituição das Florestas Protetoras, criadas por meio do Decreto no 23.793, como podemos observar com a leitura do artigo 4º do Capítulo II do citado decreto:

Serão consideradas florestas protectoras as que, por sua localização, servirem conjuncta ou separadamente para qualquer dos fins seguintes:
a) conservar o regimen das águas;
b) evitar a erosão das terras pela acção dos agentes naturaes;
c) fixar dunas;
d) auxiliar a defesa das fronteiras, de modo julgado necessário pelas autoridades militares;
e) assegurar condições de salubridade pública;
f) proteger sítios que por sua belleza mereçam ser conservados;
g) asilar especimens raros de fauna indígena; 
Ainda de acordo com o decreto supracitado, estas áreas eram consideradas de conservação perene, permanecendo em posse de seu proprietário, como se depreende do Artigo 8ํㅡㄴ transcrito a seguir.

"Consideram-se de conservação perenne, e são inalienáveis, salvo se o adquirinte se obrigar, por si, seus herdeiros e sucessores, a mantê-las sob o regimen legal respectivo, as florestas protetoras e as remanescentes".

As florestas protetoras vão permanecer de 1934 até 1965, quando são extintas pela Lei ํㅜ 4.771, de 14 de setembro (Código Florestal), mantendo-se, porém, a perpetuidade das áreas particulares protegidas como podemos observar na leitura de trecho do Artigo 6으 da referida lei, transcrito a seguir:

O proprietário da floresta não preservada, nos termos desta lei, poderá gravá-la com perpetuidade, desde que verificada a existência de interesse público pela autoridade florestal. O vínculo constará de termo assinado perante a autoridade florestal e será averbado à margem da inscrição no Registro Público.

Doze anos após, o extinto Instituto Brasileiro de Desenvolvimento Florestal (IBDF), autarquia federal ligada ao Ministério da Agricultura e encarregada de assuntos relacionados às florestas, buscando atender aos anseios de proprietários desejosos de proteger as espécies da fauna em suas propriedades, cria, então, os Refúgios Particulares de Animais Nativos, coibindo a caça. A iniciativa dá frutos e com a Portaria no $217 / 88$, é estendida a proteção às espécies da flora, com a criação das Reservas Particulares de Fauna e Flora, que viriam a ser consideradas, a partir de 1990, por meio de Decreto Federal, como RPPNs.

Finalmente em 1990, o Decreto Federal 98.914 em seu artigo 1ํ, transcrito a seguir, criava as Reservas Particulares do Patrimônio Natural (RPPN):

Art. $1^{\circ}$ - Compete ao Instituto Brasileiro do Meio Ambiente e dos Recursos Naturais Renováveis IBAMA, observadas as normas deste Decreto, reconhecer e registrar, como Reserva Particular do Patrimônio Natural, por destinação do seu proprietário, e em caráter perpétuo, imóvel do domínio privado em que, no todo ou em parte, sejam identificadas condições naturais primitivas, semiprimitivas, recuperadas, ou cujas 
características justifiquem ações de recuperação, pelo seu aspecto paisagístico, ou para a preservação do ciclo biológico de espécies da fauna ou da flora nativas do Brasil.

Importante notar na leitura atenta deste decreto, que a propriedade poderia ser reconhecida total ou parcialmente como uma RPPN, cabendo ao proprietário interessado encaminhar requerimento à Superintendência do IBAMA da unidade da federação em que o imóvel se localizava. Outro ponto importante diz respeito à preferência pela apreciação de propostas de criação de RPPN em imóveis contíguos a "florestas de preservação permanente, ou de áreas cujas características devam ser conservadas, no interesse do patrimônio natural do país" (Decreto Federal № 98.914) como reza o parágrafo único do Artigo 2 ํㅡ do citado decreto. Aqui podemos perceber a preocupação do legislador em criar zonas-tampão ou de "amortecimento", criadas no entorno das Unidades de Conservação já existentes, assegurando a sua proteção e ampliando as áreas protegidas (COSTA, 2006).

É importante observar que o Decreto Federal № 98.914, não mantinha a perpetuidade da RPPN. A propriedade poderia perder a condição de reserva particular se, por ação ou omissão de seu proprietário, tivesse alteradas as condições naturais que justificaram a sua criação. Esta possibilidade desaparece com o Decreto 1.922 de 5 de Junho de 1996 que, entre outras resoluções, mantinha o caráter perpétuo da RPPN.

Finalmente, no ano de 2000, por meio da Lei Federal № 9.985, as Reservas Particulares do Patrimônio Natural são alçadas à categoria de Unidades de Conservação. As RPPN são uma das sete categorias que constituem o grupo das Unidades de Uso Sustentável, que busca "compatibilizar a conservação da natureza com o uso sustentável de parcela dos seus recursos naturais" (Lei № 9.985, de 18 de julho de 2000 - SNUC) sendo o Brasil o único país latino americano onde as áreas particulares de preservação ambiental têm este status 


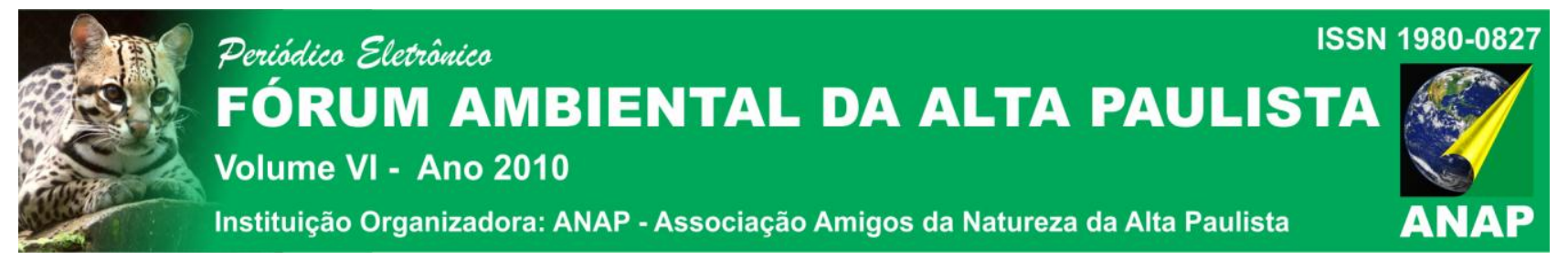

\begin{tabular}{|c|c|c|}
\hline & $\begin{array}{l}\text { Unidades de Uso } \\
\text { Sustentável }\end{array}$ & Principais Características \\
\hline I. & $\begin{array}{l}\text { Áreas de Proteção } \\
\text { Ambiental }\end{array}$ & $\begin{array}{l}\text { Área com um certo grau de ocupação humana, dotada de atributos abióticos, } \\
\text { bióticos, estéticos ou culturais especialmente importantes para a qualidade de } \\
\text { vida e o bem-estar das populações humanas, }\end{array}$ \\
\hline II. & $\begin{array}{l}\text { Áreas de Relevante } \\
\text { Interesse Ecológico }\end{array}$ & $\begin{array}{l}\text { Área de pequena extensão, com pouca ou nenhuma ocupação humana, com } \\
\text { características naturais extraordinárias ou que abriga exemplares raros da } \\
\text { biota. }\end{array}$ \\
\hline III. & Floresta Nacional & Área com cobertura florestal de espécies predominantemente nativas. \\
\hline IV. & Reserva Extrativista & $\begin{array}{l}\text { Área utilizada por populações extrativistas tradicionais, cuja subsistência } \\
\text { baseia-se no extrativismo e, complementarmente, na agricultura de } \\
\text { subsistência e na criação de animais. }\end{array}$ \\
\hline V. & Reserva de Fauna & $\begin{array}{l}\text { Área natural com populações animais de espécies nativas, terrestres ou } \\
\text { aquáticas, residentes ou migratórias, adequadas para estudos técnico- } \\
\text { científicos sobre o manejo econômico sustentável de recursos faunísticos. }\end{array}$ \\
\hline VI. & $\begin{array}{l}\text { Reserva de } \\
\text { Desenvolvimento } \\
\text { Sustentável }\end{array}$ & $\begin{array}{l}\text { Área natural que abriga populações tradicionais, cuja existência baseia-se em } \\
\text { sistemas sustentáveis de exploração dos recursos naturais, desenvolvidos ao } \\
\text { longo de gerações e adaptados às condições ecológicas locais e que } \\
\text { desempenham um papel fundamental na proteção da natureza e na } \\
\text { manutenção da diversidade biológica. }\end{array}$ \\
\hline VII. & $\begin{array}{l}\text { Reserva Particular o } \\
\text { Patrimônio Natural }\end{array}$ & $\begin{array}{l}\text { Área privada, gravada com perpetuidade, com o objetivo de conservar a } \\
\text { diversidade biológica. }\end{array}$ \\
\hline
\end{tabular}

(COSTA, 2006). A seguir elaboramos um quadro comparativo entre as Unidades de Uso Sustentável previstas na Lei no 9.985.

\title{
Quadro 1 - Unidades de Uso Sustentável
}

\author{
FONTE: Lei 9.985 de Julho de 2000
}

\section{O MUNICÍPIO DE DESCOBERTO (MG)}

Situado na Zona da Mata Mineira, mais especificamente na Microrregião de Juiz de Fora, o município de Descoberto tem por coordenadas geográficas os pontos $21,45^{\circ} \mathrm{S}$ e $42,96^{\circ} \mathrm{W}$. No mapa a seguir vemos a mesorregião da Zona da Mata Mineira.

Mapa 1 - Mesorregião da Zona da Mata Mineira 

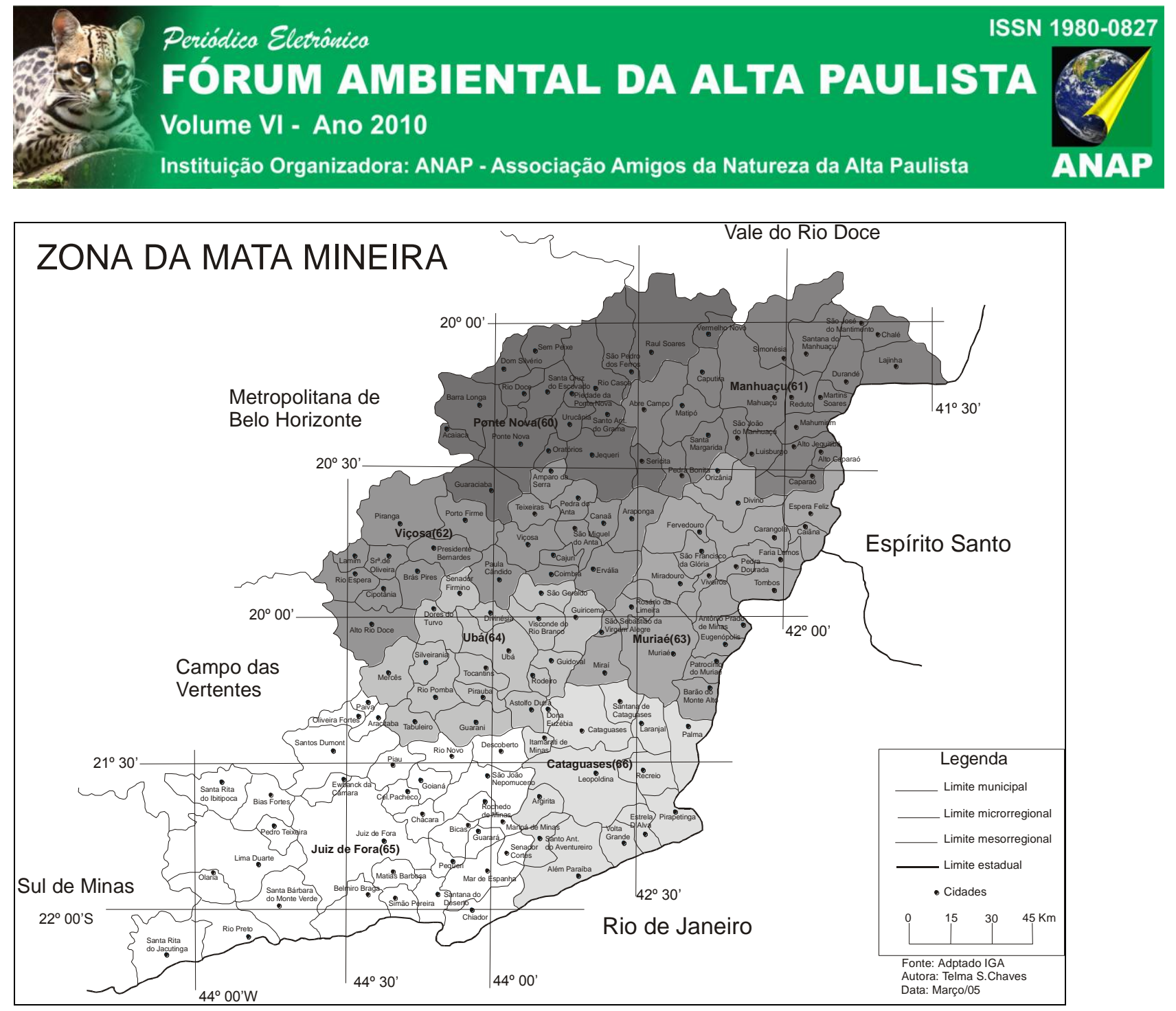

Está inserido numa região de relevo bastante acidentado, característico do domínio morfoclimático dos "Mares de Morros" outrora florestados do Brasil de Sudeste (SABER, 2003:45). Ainda segundo os ensinamentos de Aziz Ab' Saber em seu livro "Os Domínios de Natureza no Brasil", trata-se de uma grande unidade "morfoclimática e climato-botânica" de "domínio das regiões serranas, de morros mamelonares do Brasil de Sudeste". Esta é uma área de climas tropicais e subtropicais úmidos - zona da mata atlântica sul-oriental, que

na porção sul e sul-oriental de Minas Gerais apresentava um quadro tão contínuo de florestas tropicais em áreas geomorfológicas típicas de "mares de morros", que foi denominada Zona da Mata mineira. Um 
espaço de florestas tropicais que se estendia desde a porção ocidental das serranias fluminenses até Santos Dumont, Juiz de Fora e Manhuaçu, sofrendo modificações drásticas nos altiplanos campestres, dotados de ecossitemas híbridos ocorrentes entre Tiradentes e Barbacena. (SABER, 2003:49).

Em Descoberto, na localidade de Alto da Vista Alegre, está a altitude máxima registrada, atingindo $1.434 \mathrm{~m}$ e na foz do Ribeirão dos Mineiros está a altitude mínima de $355 \mathrm{~m}$, estando o centro da cidade a altitude é de $344 \mathrm{~m}$.

A temperatura média anual é de $21^{\circ} \mathrm{C}$, e o índice pluviométrico médio anual é de $1.581 \mathrm{~mm}$, com dois períodos bem definidos quanto à distribuição das chuvas, uma estação chuvosa, que vai de outubro a março e outra seca, que vai de abril a setembro, característica típica dos climas Tropicais. Descoberto faz parte da bacia hidrográfica do rio Paraíba do Sul, sendo o Ribeirão do Grama e o Rio Novo seus principais cursos d'água.

De acordo com informações do Instituto Brasileiro de Geografia e Estatística (IBGE), que cita o livro "Toponímia de Minas Gerais" do professor Joaquim Ribeiro Costa, publicado no ano de 1970, o Distrito de Descoberto teria sido criado no ano de 1841. Em 19 de Dezembro de 1965, por meio da lei no 1.265 , o Distrito do Descoberto da Santíssima Trindade foi transferido da Freguesia do Rio Novo, no município de Mar de Espanha, para a Freguesia de São João Nepomuceno, tendo sido incorporado a este município a 30 de Novembro de 1880, pela lei 2.677 .

O nome Descoberto, segundo informações obtidas no site do IBGE, teria sua origem no "topônimo alusivo, provavelmente, a lugar onde se descobriu o ouro e se estabeleceu serviço de mineração". O município, que a princípio se chamou Descoberto do Rio Novo, foi criado pela Lei № 1.039 de Dezembro de 1953, em território desmembrado do município vizinho de São João Nepomuceno, sendo sua instalação do ano de 1954.

De acordo com estimativas recentes do IBGE a população de Descoberto é de aproximadamente 5.126 habitantes (2009), distribuídos por uma 
área de $213,20 \mathrm{~km}^{2}$. Seus moradores desempenham atividades nos três setores econômicos, primário, secundário e terciário, com destaque para o setor de serviços, principal atividade econômica local. O PIB descobertense em 2007, considerando-se o valor adicionado bruto dos serviços, era de $R \$ 16.789,00$, valor baixo se comparado com os PIBs de São João Nepomuceno ( $R \$ 103.829,00)$, Leopoldina ( $R \$ 277.073,00)$, Itamarati de Minas $(R \$ 16.990,00)$, Astolfo Dutra $(R \$ 51.157,00)$, Guarani $(R \$ 31.040,00)$ e Rio Novo $(R \$ 32.115,00)$, seus vizinhos imediatos.

\section{A RPPN ALTO DA BOA VISTA}

A reserva particular Alto da Boa Vista localiza-se no extremo leste e na encosta sul da Serra do Relógio, na divisa dos municípios de Descoberto, Guarani e Astolfo Dutra. Ocupa uma área de aproximadamente 140ha, dos quais $85 \%$ são destinados à preservação. A Serra do Relógio é um divisor de águas com nascentes que abastecem os rios Novo e Pomba. São seis os cursos d'água que cortam a reserva e que são "berço para caranguejos, cágados e moluscos, principalmente na várzea situada a cerca de mil metros de altitude, que os moradores veneram como um local sagrado." (RIBEIRO, 2O07:155)

A reserva apresenta ecossistemas distintos que obedecem a uma variação de altitude de cerca de $600 \mathrm{~m}$, como é o caso dos campos rupestres que podem ser observados no pico da Serra do Relógio, a uma altitude de $1.434 \mathrm{~m}$. Este é o hábitat de várias espécies da fauna local como é o caso de aves como o corujão, o araçari e o gavião-rei e de mamíferos como quatis, tamanduás, jaguatiricas e lobos-guará, animas que, como nas palavras do proprietário da reserva "chegam a entrar dentro de casa, ouriço, gambá, cuíca, cobra... chega a assustar". Ainda segundo Helvécio: "temos um cachorro para controlar isso, senão fica perigoso, já vi jaguatirica em volta de casa." 
Hoje a mata está regenerada em mais de $85 \%$ da propriedade, resultado de dezessete anos de trabalho de seu proprietário, tempo em que nenhuma árvore nativa foi derrubada. O resultado é que " $20 \%$ da floresta é primária, sem alterações notáveis, e o restante encontra-se em estágio avançado de recuperação" (RIBEIRO, 2007:155). São espécies vegetais como a Canjerana, o Jequitibá e os Cedros que despontam na paisagem local.

Como agrônomo, assim que chegou à propriedade, Helvécio se dedicou à agropecuária, mas as características climáticas e a declividade do terreno forçaram-no a mudar de atividade. A apicultura foi a saída econômica encontrada, o que the permitia comercializar o mel produzido. Adotando práticas orgânicas, cultivava morangos, pimenta, feijão e mandioca, além da silvicultura com a plantação de eucaliptos para a produção de lenha e moirões para cerca, atividade bastante difundida entre os proprietários rurais de Descoberto e região.

Helvécio nos diz, no capítulo do livro "Minha terra protegida, histórias das RPPNs da Mata Atlântica" dedicado à RPPN Alto da Boa Vista que:

"tentei continuar com a agropecuária pesada, mas não deu certo, aprendi então a me guiar pela preservação. É uma satisfação ver a natureza se regenerar. E no aspecto humano, cresceu o reconhecimento do meu trabalho por parte das comunidades".

A principal finalidade da RPPN Alto da Boa Vista é a proteção das espécies da fauna e da flora e a recomposição dos remanescentes florestais alterados (RIBEIRO, 2007:158). Para elevar o potencial turístico da propriedade, Helvécio se concentrou na construção de uma pousada e um centro de visitantes com o intuito de atender à demanda mensal que varia de 30 a 40 pessoas, que buscam o lugar para as mais variadas atividades, desde a prática de atividades esportivas como o montanhismo e o trekking, cavalgadas, passando por grupos de escoteiros.

As atividades desenvolvidas na RPPN são voltadas para 
"públicos com dois perfis. O primeiro, de estudantes do ensino fundamental - cuja visita é estimulada por uma parceria com a Secretaria de Educação de Descoberto e outros municípios vizinhos - que assistem à apresentação no auditório do centro, percorrem uma trilha de baixo nível de dificuldade e recebem informações sobre hidrologia, geografia, biodiversidade, história de exploração e restauração dos recursos naturais locais" (RIBEIRO, 2007:158).

Quanto ao segundo grupo de visitantes, "conta com hospedagem, alimentação, guia e excursões aos atrativos de médio grau de dificuldade - e esses pagam pelos serviços da RPPN”. (RIBEIRO, 2007:158).

Dessa forma, cumpre-se o disposto no Artigo 21 da Lei 9.985 (SNUC), que em seu parágrafo $2^{\circ}$, inciso II que diz que só poderá ser permitida, na Reserva Particular do Patrimônio Natural, conforme se dispuser em regulamento: II - a visitação com objetivos turísticos, recreativos e educacionais;

Podemos apontar ainda outro benefício trazido à região pela RPPN Alto da Boa Vista que é o recebimento por parte do município de Descoberto do ICMS Ecológico, uma verba federal repassada aos municípios onde existem unidades de conservação. O ICMS Ecológico foi criado pela Lei Estadual no 12.040 de 28 de dezembro de 1995, mais conhecida como Lei Robin Hood. Da leitura atenta do seu Artigo 1ํㅜ inciso VIII - relativo ao meio ambiente - alínea b, transcrito adiante, podemos entender que uma parcela do ICMS:

\begin{abstract}
"será distribuído com base no Índice de Conservação do Município, calculado de acordo com o Anexo IV desta lei, considerando-se as unidades de conservação estaduais, federais e particulares, bem como as unidades municipais que venham a ser cadastradas, observados os parâmetros e os procedimentos definidos pelo órgão ambiental estadual".
\end{abstract}

Até o ano de 2000, a RPPN Alto da Boa Vista era a única unidade de conservação na região de Descoberto, porém a iniciativa de Helvécio deu frutos e ele afirma, ainda em relação à arrecadação de ICMS pela prefeitura municipal, que: "Agora criaram outras, parece que virão 700 reais por mês, mas quase 
metade ainda é devida a nossa área. Entre 1996 e 2006, soube que o ICMS rendeu mais de 30 mil reais..." (RIBEIRO, 2007:159).

A beleza de propriedades preservadas como a RPPN Alto da Boa Vista tem o poder de transformar seus visitantes em parceiros da preservação ambiental e multiplicadores do conceito de desenvolvimento sustentável, que como nas palavras de John Swarbrooke, é o "desenvolvimento que satisfaz nossas necessidades hoje, sem comprometer a capacidade das pessoas satisfazerem as suas no futuro" (SWARBROOKE, 2000:3). Esta é a idéia do proprietário da Alto da Boa Vista que afirma:

"Até já consultei advogado pra saber se há uma forma de não mexerem nisso quando eu me for. Minha idéia é deixar uma estrutura bem montada que quando minhas filhas herdarem a reserva, ela continue funcionando e gerando renda, mesmo que não queiram tocar". (RIBEIRO, 2007:152)

Durante as visitas guiadas, os turistas identificam problemas causados pela ação do homem na região como o extrativismo e têm, no exemplo de Helvécio, uma aula de educação ambiental.

A importância desta e de outras RPPNs, se debruça no fato inconteste de que esta geração e as gerações futuras terão de conviver e se relacionar com aquilo que restou de anos e anos de exploração humana nos domínios da Mata Atlântica e a necessidade de preservar estes pequenos extratos florestais é primordial. De acordo com os estudos do professor de história da Universidade de Nova York, Warren Dean, "Certa extensão de cobertura florestal ainda existe na região e, embora a maior parte seja identificável como secundária, algumas pequenas faixas podem jamais ter sido derrubadas ou queimadas pelo homem". (DEAN, 1996:31).

Em tempos de discussões acaloradas na Câmara Federal em torno da modificação da Legislação Ambiental no Brasil e a aprovação do Novo Código Florestal Brasileiro, reforçamos a importância das RPPNs como forma de 
assegurar a preservação do que restou da Mata Atlântica. Este artigo cumpre a função de divulgar a iniciativa de advogados, médicos, biólogos, agrônomos, artistas e outros que se unem em torno de um mesmo ideal: a preservação ambiental.

\section{BIBLIOGRAFIA}

AB' SABER, Aziz. Os Domínios de Natureza no Brasil: Potencialidades Paisagísticas. São Paulo: Ateliê Editorial, 2003.

COSTA, Cláudia Maria Rocha. RPPN Mata Atlântica: Potencial para a Implantação de Políticas de Incentivo às RPPNs. Belo Horizonte: Conservação Internacional, Fundação SOS Mata Atlântica, The Nature Conservancy, 2006.

RIBEIRO, Heloisa Bio. Minha terra protegida: histórias das rppns da Mata Atlântica. Belo Horizonte: Conservação Internacional, 2007.

SWARBROOKE, John. Turismo Sustentável: Conceitos e Impacto Ambiental. São Paulo: Aleph, 2000.

DEAN, Warren. A ferro e fogo: a história e a devastação da Mata Atlântica brasileira. São Paulo: Companhia das Letras, 1996.

BRASIL. Decreto no 23.793, de 23 de janeiro de 1934. Disponível em: <http://www.jusbrasil.com.br/legislacao/116688/decreto-23793-34>. Acesso em: 06 JUL. 2010.

BRASIL. Lei no 9.985, de 18 de julho de 2000. Disponível em: <http://www.planalto.gov.br/ccivil_03/leis/L9985.htm>. Acesso em: 06 JUL. 2010.

BRASIL. Lei no 4.771, de 14 de setembro de 1965. Disponível em: <http://www.planalto.gov.br/ccivil_03/Leis/L4771.htm>. Acesso em: 06 JUL. 2010.

BRASIL. Decreto no 98.914, de 31 de janeiro de 1990. Disponível em: <http://www.jusbrasil.com.br/legislacao/114290/decreto-98914-90>. Acesso em 05 MAI. 2010. 


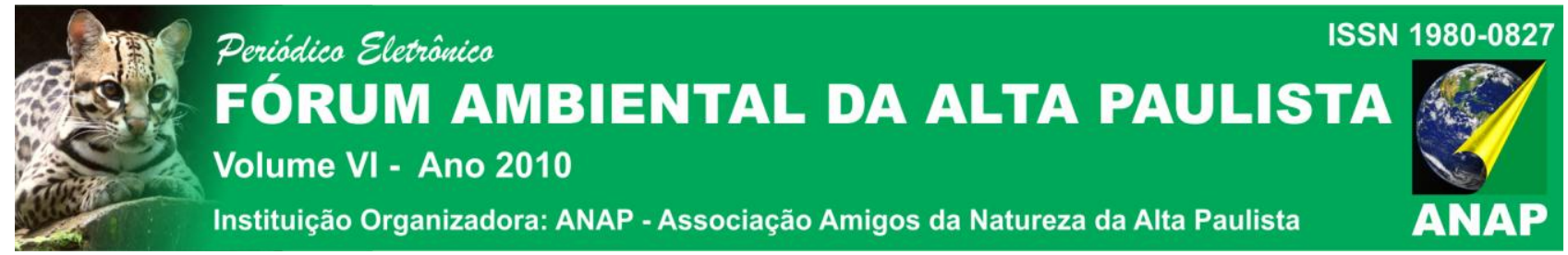

BRASIL. Decreto no 1.922, de 5 de junho de 1996. Disponível em: <http://www.jusbrasil.com.br/legislacao/109708/decreto-1922-96>. Acesso em: 05 MAI. 2010.

MINAS GERAIS. Lei no 12.040, de 28 de dezembro de 1995. Disponível em: <http://www.fjp.gov.br/produtos/cees/robin_hood/lei12040.pdf>. Acesso em: 05 MAI. 2010.

IBGE - www.ibge.gov.br 